\title{
Penentuan Supplier Bahan Baku Restaurant XO Suki Menggunakan Metode Weight Product
}

\author{
Futiami Laila ${ }^{1}$, Anita Sindar ${ }^{2}$ \\ 1,2STMIK Pelita Nusantara, Teknik Informatika, Indonesia \\ futiamilaila1994@gmail.com ${ }^{1}$, haito_ita@yahoo.com²
}

\begin{abstract}
Abstrak
Setiap perusahaan harus menjaga kualitas produksi maka diperlukan bahan yang mempunyai kualitas tinggi juga. Beberapa jasa pemasok bahan baku berlomba-lomba memberikan referensi dan keuntungan pada perusahaan. Pengambil keputusan harus dapat menentukan supplier yang tepat dalam menyediakan bahan baku Restaurant XO Suki, SPK dengan metode Weight Product merupakan Sistem Pengambil Keputusan (SPK) berbasis komputer. Kriteria dalam pemilihan supplier : kualitas (K1) Bobot = 3, pelayanan (K2) Bobot = 5, Harga (K3) Bobot = 3, Pengirim (K4) Bobot =4, Fleksibilitas (K5) Bobot $=2$. Perhitungan WP, yang baik adalah menghasilkan nilai alternatif tertinggi. Implementasi metode Weight Product menginformasikan nilai dari setiap alternatif sehingga pengambil keputusan akhir dapat menunjuk supplier dengan penilaian yang rasional berbasis sistem komputer.
\end{abstract}

Keywords - Supplier, DSS, Weight Product, Vektor, Alternative Value

\section{Latar Belakang}

Restaurant XO Suki, salah satu restoran yang sedang berkembang, agar mampu menghasilkan produk/menu makanan yang berkualitas sesuai dengan keinginan customer, Resturant XO Suki ingin melakukan perbaikan terhadap salah satu proses bisnis yang selama ini berjalan di perusahaan, bagian procurement. Masalah utama perusahaan yaitu keterlambatan pengiriman bahan baku yang akan digunakan dalam proses produksi sehingga mengakibatkan proses produksi menjadi terhambat. Alasan lainnya supplier harus mengirimkan bahan baku ke beberapa perusahaan lain dalam waktu bersamaan. Bahan baku menjadi penentu kualitas menu makanan. Pemasok bahan baku pada restoran tidak satu atau dua supplier.

Pemasok berlomba-lomba memberikan referensi bahan sesuai keunggulan produksi. Bahan baku yang segar, warna menarik, mampu bertahan dalam waktu lama, dan harga lebih murah menjadi beberapa dasar memilih kategori supplier. Berkaitan dengan proses pemilihan supplier dalam pengadaan bahan baku makanan ataupun penunjang dalam proses produksi. Perusahaan membutuhkan sebuah Sistem Pengambil Keputusan (SPK) yang mampu memberikan solusi berbasis komputer dalam menentukan supplier pemasok bahan baku restoran [1].

Keputusan sistem yang tepat memberikan informasi yang up to date didukung metode SPK, dalam permasalahan ini dipergunakan Weight Product (WP). WP menggunakan perkalian untuk menghubungkan rating atribut, rating setiap atribut harus dipangkatkan dengan bobot atribut yang bersangkutan. Proses tersebut sama halnya dengan normalisasi. Weighted Product dapat membantu dalam mengambil keputusan akan tetapi perhitungan dengan menggunakan metode WP hanya menghasilkan nilai terbesar yang akan terpilih sebagai alternatif yang terbaik [2].

Perhitungan akan sesuai dengan metode ini apabila alternatif yang terpilih memenuhi kriteria yang telah ditentukan. Penentuan pemilihan supplier bahan baku dengan Weighted Product (WP) merupakan sebuah kerangka untuk mengambil keputusan dengan efektif atas persoalan dengan menyederhanakan dan mempercepat proses pengambilan keputusan dengan memecahkan persoalan tersebut kedalam bagian-bagiannya [3].

Dalam penelitian sebelumnya berjudul, implementasi metode Weighted Product (WP) pada sistem pendukung keputusan seleksi calon karyawan BPJS kesehatan Tasikmalaya, dijelaskan dari menu perangkingan nilai terbesar ada pada alternatif A5 (Deni Waja) merupakan alternatif yang terpilih sebagai alternatife [4].

\section{Metode}

A. Konsep Sistem Pengambil Keputusan Sistem Pendukung Keputusan (SPK) merupakan suatu pendekatan atau metodelogi untuk mendukung 
keputusan. SPK menggunaka CBIS (Computer Based Information System) yang fleksibel, interaktif dan dapat diadaptasi, yang dikembangkan untuk mendukung solusi untuk masalah manajemen spesifik yang tidak terstruktur. Sitem Pengambil Keputusan menggunakan data, memberikan antarmuka pengguna yang mudah dan dapat menggabungkan pemikiran pengambil keputusan [5].

Sistem pendukung keputusan dibangun oleh tiga komponen utama yaitu :

\section{Subsistem Data (Database)}

Data disimpan untuk diorganisasikan dalam sebuah basis data yang diorganisasikan oleh suatu sistem yang disebut dengan sistem manajemen basis data (Database Management System).

2. Subsistem Model (Model Base)

Model adalah suatu tiruan dari alam nyata. Kendala yang sering dihadapi dalam merancang model adalah bahwa model yang dirancang tidak mampu mencerminkan seluruh variabel alam nyata, sehingga keputusan yang diambil tidak sesuai dengan kebutuhan.

3. Subsistem Dialog (User System Interface)

Subsistem dialog adalah fasilitas yang mampu mengintegrasikan sistem yang terpasang dengan pengguna secara interaktif, yang dikenal dengan subsistem dialog.

\section{B. Weighted Product (WP)}

Metode Weighted Product (WP) menggunakan perkalian untuk menghubungkan rating atribut, dimana rating setiap atribut harus dipangkatkan dulu dengan bobot yang bersangkutan [6], [7] :

Preferensi untuk alternative Si :

$$
\mathrm{Si}=\prod_{\mathrm{J}=1}^{\mathrm{n}} \mathrm{Xij}{ }^{\mathrm{Wj}}
$$

dengan $\mathrm{i}=1,2, \ldots, \mathrm{m}$. dimana :

$\mathrm{S}$ : Preferensi alternatif dianologikan sebagai vektor $\mathrm{S}$

$X$ : Nilai kriteria

W : Bobot kriteria/subkriteria

I : Alternatif

$\mathrm{j}:$ Kriteria

$\mathrm{n}$ : Banyaknya kriteria

$\Sigma \mathrm{Wj}=1$. Wj adalah pangkat bernilai positif untuk atribut keuntungan dan bernilai negatif untuk atribut biaya. Preferensi relatif dari setiap alternatif, diberikan sebagai:

$$
\mathrm{Vi}=\frac{\prod_{\mathrm{J}=1}^{\mathrm{n}} \mathrm{Xij}{ }^{\mathrm{Wj}}}{\prod_{\mathrm{j}=1}^{\mathrm{m}}\left(\mathrm{Xj}^{*}\right)}
$$

V : Preferensi alternatif dianalogikan sebagai vektor $\mathrm{V}$

$X$ : Nilai Kriteria

W : Bobot kriteria/subkriteria i : Alternatif

$\mathrm{j}:$ Kriteria

$\mathrm{n}$ : Banyaknya kriteria

* : Banyaknya kriteria yang telah dinilai pada vektor $\mathrm{S}$

Langkah-langkah metode WP [8], [9], [10] :

1. Mengalikan seluruh atribut bagi sebuah alternatif dengan bobot sebagai pangkat positif untuk atribut manfaat dan bobot berfungsi sebagai pangkat negatif pada atribut biaya.

2. Hasil perkalian dijumlahkan untuk menghasilkan nilai pada setiap alternatif.

3. Mencari nilai alternatif dengan melakukan langkah yang sama seperti langkah satu, hanya saja menggunakan nilai tertinggi untuk setiap atribut tertinggi untuk setiap atribut manfaat dan terendah untuk atribut biaya.

4. Membagi nilai $V$ bagi setiap alternatif dengan nilai standar $\left(\mathrm{V}\left(\mathrm{A}^{*}\right)\right)$ yang menghasilkan $\mathrm{R}$.

5. Ditemukan urutan alternatif terbaik yang akan menjadi keputusan.

\section{Pemodelan Sistem}

Perancangan sistem digambarkan menggunakan flowchart. Flowchart atau diagram alir adalah sekumpulan simbol-simbol atau skema yang menunjukkan atau menggambarkan rangkaian kegiatan proses program dari awal sampai dengan akhir proses, inti pembuatan diagram alir tersebut untuk menggambarkan urutan langkah-langkah pengerjaan dari metode program.

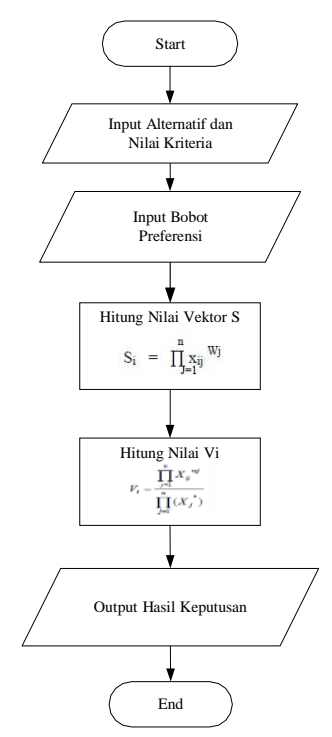

Gambar 1. Flowchart Sistem

\section{Hasil}


Algoritma merupakan urutan-urutan penyelesaian masalah yang dalam hal ini menggunakan metode Weighted Product (WP). Adapun tahapan-tahapan dalam metode WP:

1. Menentukan Kriteria Penilaian

2. Menentukan Alternatif yang akan dinilai.

3. Mengalihkan seluruh atribut kriteria bagi seluruh alternatif dengan bobot.

4. Hasil perkalian dijumlahkan untuk menghasilkan nilai pada setiap alternative.

5. Membagi nilai Vi bagi setiap alternatif dengan nilai pada setiap alternative.

6. Ditemukan urutan alternatif terbaik yang akan menjadi keputusan.

Tabel 1. Kriteria

\begin{tabular}{clc}
\hline Kode & \multicolumn{1}{c}{ Kriteria Penilaian } & Bobot \\
\hline K1 & Kualitas & 3 \\
K2 & Pelayanan & 5 \\
\hline K3 & Harga & 3 \\
\hline K4 & Pengiriman & 4 \\
\hline K5 & Fleksibilitas & 2 \\
\hline
\end{tabular}

Rating kecocokan setiap alternatif pada setiap kriteria dinilai dengan satu sampai 5, yaitu:

Tabel 2. Bobot Untuk Penilaian

\begin{tabular}{ccl}
\hline Nilai & Bobot & Keterangan \\
\hline $80-100$ & 5 & Sangat Baik \\
\hline $60-79$ & 4 & Baik \\
\hline $40-59$ & 3 & Cukup \\
\hline $20-39$ & 2 & Buruk \\
\hline $0-19$ & 1 & Sangat Buruk \\
\hline
\end{tabular}

Alternatif dalam hal ini adalah supplier. Supplier yang digunakan sebagai sampel kasus ada 6 data nama supplier, N001 $=$ CV. Mega Nusantara, N002 $=$ CV. Sumber Jaya, N003 = PT. Graha Mitra Mandiri, N004 = CV. Arumdaeun, N005 = PT. Perkasa Food, N006 = CV. Wijayamas. Setelah alternatif ditentukan, langkah selanjutnya yaitu menentukan nilai kriteria tiap supplier yang akan dinilai kelayakannya, Tabel 3.

Tabel 3. Nilai Alternatif Setiap Kriteria

\begin{tabular}{|c|c|c|c|c|c|c|}
\hline No & Alternatif & K1 & K2 & K3 & K4 & K5 \\
\hline 1 & $\begin{array}{l}\text { CV. Mega } \\
\text { Nusantara }\end{array}$ & 75 & 90 & 75 & 80 & 82 \\
\hline 2 & CV. Sumber Jaya & 74 & 90 & 77 & 75 & 77 \\
\hline 3 & $\begin{array}{l}\text { PT. Graha Mitra } \\
\text { Mandiri }\end{array}$ & 75 & 85 & 75 & 80 & 75 \\
\hline 4 & CV. Arumdaeun & 76 & 85 & 73 & 80 & 75 \\
\hline 5 & PT. Perkasa Food & 75 & 90 & 75 & 86 & 78 \\
\hline 6 & CV. Wijayamas & 82 & 90 & 77 & 80 & 74 \\
\hline \multicolumn{7}{|c|}{ Tabel 4 Nilai Kriteria } \\
\hline Kode & \multicolumn{2}{|c|}{ Kriterian Penilaian } & Bobot & \multicolumn{2}{|c|}{$\begin{array}{l}\text { Perbaikan } \\
\text { Bobot }\end{array}$} & \\
\hline K1 & \multicolumn{2}{|l|}{ Kualitas } & 3 & \multicolumn{2}{|c|}{0,176} & \\
\hline
\end{tabular}

\begin{tabular}{llll}
\hline K2 & Pelayanan & 5 & 0,294 \\
\hline K3 & Harga & 3 & 0,176 \\
\hline K4 & Pengiriman & 4 & 0,235 \\
\hline K5 & Fleksibilitas & 2 & 0,117 \\
\hline
\end{tabular}

Selanjutnya adalah menghitung Vektor $\mathrm{S}$, data-data akan dikalikan, tetapi sebelumnya dilakukan pemangkatan dengan bobot dari tiap alternatif yaitu:

a) Vektor S1 (CV. Mega Nusantara) $\left(75^{0,176}\right)\left(90^{0,294}\right)\left(75^{0,176}\right)\left(80^{0,235}\right)\left(82^{0,117}\right)$

$$
2,138 \times 3,754 \times 2,138 \times 2,800 \times 1,674=80,484
$$

b) Vektor S2 (CV. Sumber Jaya) $\left(74^{0,176}\right)\left(90^{0,294}\right)\left(77^{0,176}\right)\left(75^{0,235}\right)\left(77^{0,117}\right)$

$2,132 \times 3,754 \times 2,147 \times 2,758 \times 1,662=78,87$

c) Vektor S3 (PT. Graha Mitra Mandiri) $\left(75^{0,176}\right)\left(85^{0,294}\right)\left(75^{0,176}\right)\left(80^{0,235}\right)\left(75^{0,117}\right)$ $2,138 \times 3,691 \times 2,138 \times 2,800 \times 1,657=78,321$

d) Vektor S4 (CV. Arumdaeun) $\left(76^{0,176}\right)\left(85^{0,294}\right)\left(73^{0,176}\right)\left(80^{0,235}\right)\left(75^{0,117}\right)$ $2,143 \times 3,691 \times 2,127 \times 2,800 \times 1,657=78,131$

e) Vektor S5 (PT. Perkasa Food) $\left(75^{0,176}\right)\left(90^{0,294}\right)\left(75^{0,176}\right)\left(86^{0,235}\right)\left(78^{0,117}\right)$ $2,138 \times 3,754 \times 2,138 \times 2,848 \times 1,664=81,386$

f) Vektor S6 (CV. Wijayamas) $\left(82^{0,176}\right)\left(90^{0,294}\right)\left(77^{0,176}\right)\left(80^{0,235}\right)\left(74^{0,117}\right)$ $2,171 \times 3,754 \times 2,147 \times 2,800 \times 1,654=81,157$

Setelah nilai Vektor S didapat, maka selanjutnya adalah dengan menjumlahkan seluruh $\mathrm{S}$ untuk menghitung nilai Vi sebagai berikut :

a) $V 1=\frac{80,484}{80,484+78,870+78,321+78,131+81,386+81,157}$

$$
=0,1683
$$

b) $\mathrm{V} 2=\frac{78,870}{80,484+78,870+78,321+78,131+81,386+81,157}$

$$
=0,1649
$$

c) $\mathrm{V} 3=\frac{78,321}{80,484+78,870+78,321+78,131+81,386+81,157}$

$$
=0,1637
$$

d) V4 $=\frac{78,131}{80,484+78,870+78,321+78,131+81,386+81,157}$ $=0,1633$

e) $V 5=\frac{81,386}{80,484+78,870+78,321+78,131+81,386+81,157}$ $=0,1701$

f) $V 6=\frac{81,157}{80,484+78,870+78,321+78,131+81,386+81,157}$ $=0,1697$

Dari perhitungan sebelumnya diperoleh nilai Vi untuk setiap alternatif. Adapun yang ditetapkan sebagai kasubbag tata usaha adalah yang memiliki nilai tertinggi yaitu PT. Perkasa Food. Rincian keputusan, Tabel 4.

Tabel 5. Hasil Penilaian Alternatif

No Nama Nilai Hasil Keterangan

Program Studi Teknik Informatika 


\begin{tabular}{clcc}
\hline 1 & CV. Mega Nusantara & 0,1683 & - \\
\hline 2 & CV. Sumber Jaya & 0,1649 & - \\
\hline 3 & $\begin{array}{l}\text { PT. Graha Mitra } \\
\text { Mandiri }\end{array}$ & 0,1637 & - \\
\hline 4 & CV. Arumdaeun & 0,1633 & - \\
\hline 5 & PT. Perkasa Food & 0,1701 & $\begin{array}{c}\text { Suplier } \\
\text { Terpilih }\end{array}$ \\
\hline 6 & CV. Wijayamas & 0,1697 & - \\
\hline
\end{tabular}

Nilai hasil yang diperoleh CV. Mega Nusantara $=0,1683$, CV. Sumber Jaya $=0,1649$, PT. Graha Mandiri $=0,1637$, CV. Arumdaeun =0,1633, CV. Wijayamas $=0,1697$. PT. Perkasa Food $=0,1701$, Nilai terbesar $=0,1701$ ada pada PT. Perkasa Food sehingga alternatif PT. Perkasa Food merupakan alternatif yang terpilih sebagai alternatif terbaik.

\section{Kesimpulan}

1. Nilai bobot preferensi tiap kriteria menjadi dasar perhitungan Metode Weight Product, dari nilai hasil yang diperoleh alternatif tertinggi menjadi alternatif terbaik.

2. Implementasi metode Weight Product menginformasikan nilai dari setiap alternatif sehingga pengambil keputusan akhir dapat segera menunjuk supplier dengan penilaian yang rasional berbasis sistem komputer.

\section{Acknowledgement}

Ucapan terima kasih pada seluruh Civitas Penusa Medan dan Independent Researcher ASST.

\section{References}

[1] Muhammad Arifin Setyawan, Sri Winiarti, Sistem Pendukung Keputusan Untuk Menentukan Supplier Terbaik Menggunakan Metode Weighted Product, Jurnal Sarjana Teknik Informatika, Volume 2 Nomor 3, Oktober 2014.

[2] Heru Supriyono, Chintya Purnama Sari, Pemilihan Rumah Tinggal Menggunakan Metode Weighted Product,

KHAZANAH INFORMATIKA, Vol. I No. 1, hal. 23-29, Desember 2015.

[3] E Wiyanti, A Sindar Implementasi Analytical Hierarchy Process dalam Menentukan Tingkat Kepuasan Pelayanan E-ktp (Studi Kasus Kantor Camat Pagar Merbau), Jurnal Nasional Komputasi dan Teknologi Informasi, Vol. I No. 2, hal. 93-80, 2018.

[4] Cepi Rahmat Hidayat, Teuku Mufizar, Muhamad Dadan Ramdani, Implementasi Metode Weighted Product (Pp) Pada Sistem Pendukung Keputusan Seleksi Calon Karyawan Bpjs Kesehatan Tasikmalaya, Konferensi Nasional Sistem Informasi, hal 530-541, Tahun 2018.

[5] Artanti Rim Saulina Manik, Bowo Nurhadiyono, Yuniarsi Rahayu, Implementasi Metode Weighted Product (WP) Dalam Sistem Pendukung Keputusan Untuk Menyeleksi Penerima Beras Masyarakat Miskin (Raskin), Techno.COM, Vol. 14, No. 2, hal. 109-114 Mei 2015.

[6] Rahayu, S., \& RMS, A, Penerapan Metode Naive Bayes Dalam Pemilihan Kualitas Jenis Rumput Taman CV. Rumput Kita Landscape. Digital Zone: Jurnal Teknologi Informasi Dan Komunikasi, 9(2), 162-171, 2018.

[7] Dyna Marisa Khairina, Dio Ivando, Septya Maharani, Implementasi Metode Weighted Product Untuk Aplikasi Pemilihan Smartphone Android, Jurnal Infotel Vol. 8 No.1 hal. 16-24, Mei 2016.

[8] Nur Rohmah, Dwi Remawati, Andriani KKW, Penerapan Metode Weighted Product (Wp) Untuk Penerimaan Pegawai Baru Di PT Tiga Serangkai Pustaka Mandiri Surakarta, Jurnal IImiah SINUS Tahun

[9] Heliza Rahamania Hatta, Muhammad Rizaldi, Dyna Marisa Khairina3Penerapan Metode Weighted Product Untuk Pemilihan Lokasi Lahan Baru Pemakaman Muslim Dengan Visualisasi Google Maps, TEKNOSI, Vol. 02, No. 03, hal. Desember 2016.

[10] Dwi Cahyanto Yoni, Hindayati Mustafidah, Penerapan Metode WP (Weighted Product) Untuk Pemilihan Mahasiswa Lulusan Terbaik Di Fakultas Teknik Universitas Muhammadiyah Purwokerto, 